\title{
Junctional Neurulation : A Junction between Primary and Secondary Neural Tubes
}

\author{
Kyung Hyun Kim, Ji Yeoun Lee ${ }^{1,2}$ \\ Division of Pediatric Neurosurgery, Seoul National University Children's Hospital, Seoul, Korea \\ Department of Anatomy and Cell Biology, ${ }^{2}$ Seoul National University College of Medicine, Seoul, Korea
}

Recent case reports of junctional neural tube defect (JNTD) which is a peculiar type of spinal anomaly showing the functional disconnection of the primary and secondary neural tubes has risen interest in the process of junctional neurulation (the connection between the two neural tubes) during development. This article summarizes the clinical features of the JNTD and reviews the literature on the basic research on junctional neurulation.

Key Words : Junctional neurulation · Junctional neural tube defect · Neurulation.

\section{INTRODUCTION}

Neural tube development in humans involves two separate processes : primary and secondary neural tube formation. Although the two neurulation processes were studied extensively, the process of the connection of the two neural tubes, called 'junctional neurulation', was not clarified. A new disease entity, namely, junctional neural tube defect (JNTD), was discussed and recently recognized among clinicians as a form of congenital spinal dysraphism. However, the pathoembryogenesis of JNTD relies on speculation because there are ambiguities in junctional neurulation. Therefore, there are no proper management protocols for the JNTD.

The present paper reviews the current knowledge on junctional neurulation. We introduce some studies on the confusing and complex processes of junctional neurulation and look at the pathoembryogenesis of the JNTD, which likely occurs during the junctional neurulation period.

\section{CLINICAL IMPLICATION OF JUNCTIONAL NEU- RULATION}

Eibach et al. ${ }^{7)}$ recently described a 'new' type of spinal dysraphism. The cases showed a striking appearance of a 'disconnected' spinal cord, where a relatively normal-looking lower spinal cord is connected to the upper spinal cord via a thin fibrous band-like structure. The authors coined the condition JNTD. After the first report by Eibach et al. ${ }^{7}$, eight cases of JNTD were reported in the literature (Table 1).

The level of spinal cord disconnection in JNTD is primarily confined to the thoracolumbar region (Fig. 1). The separate

- Received : January 25, 2021 •Revised : February 8, 2021 •Accepted : February 26, 2021

- Address for reprints : Ji Yeoun Lee

Department of Anatomy and Cell Biology, Seoul National University College of Medicine, 103 Daehak-ro, Jongno-gu, Seoul 03080, Korea

Tel : +82-2-740-8205, Fax : +82-2-745-3489, E-mail : femiddang@gmail.com, ORCID : https://orcid.org/0000-0003-0464-7605

This is an Open Access article distributed under the terms of the Creative Commons Attribution Non-Commercial License (http://creativecommons.org/licenses/by-nc/4.0) which permits unrestricted non-commercial use, distribution, and reproduction in any medium, provided the original work is properly cited. 


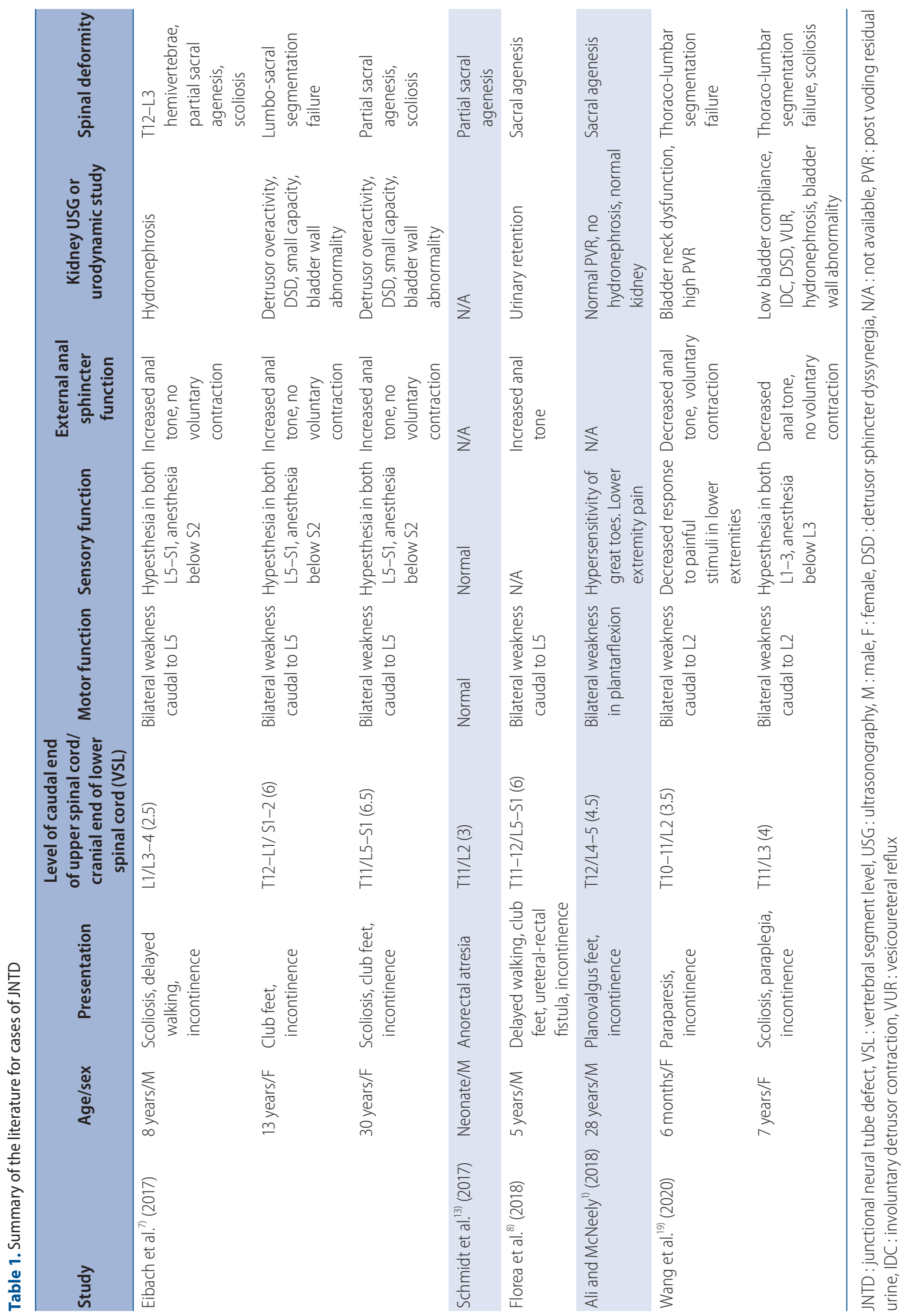



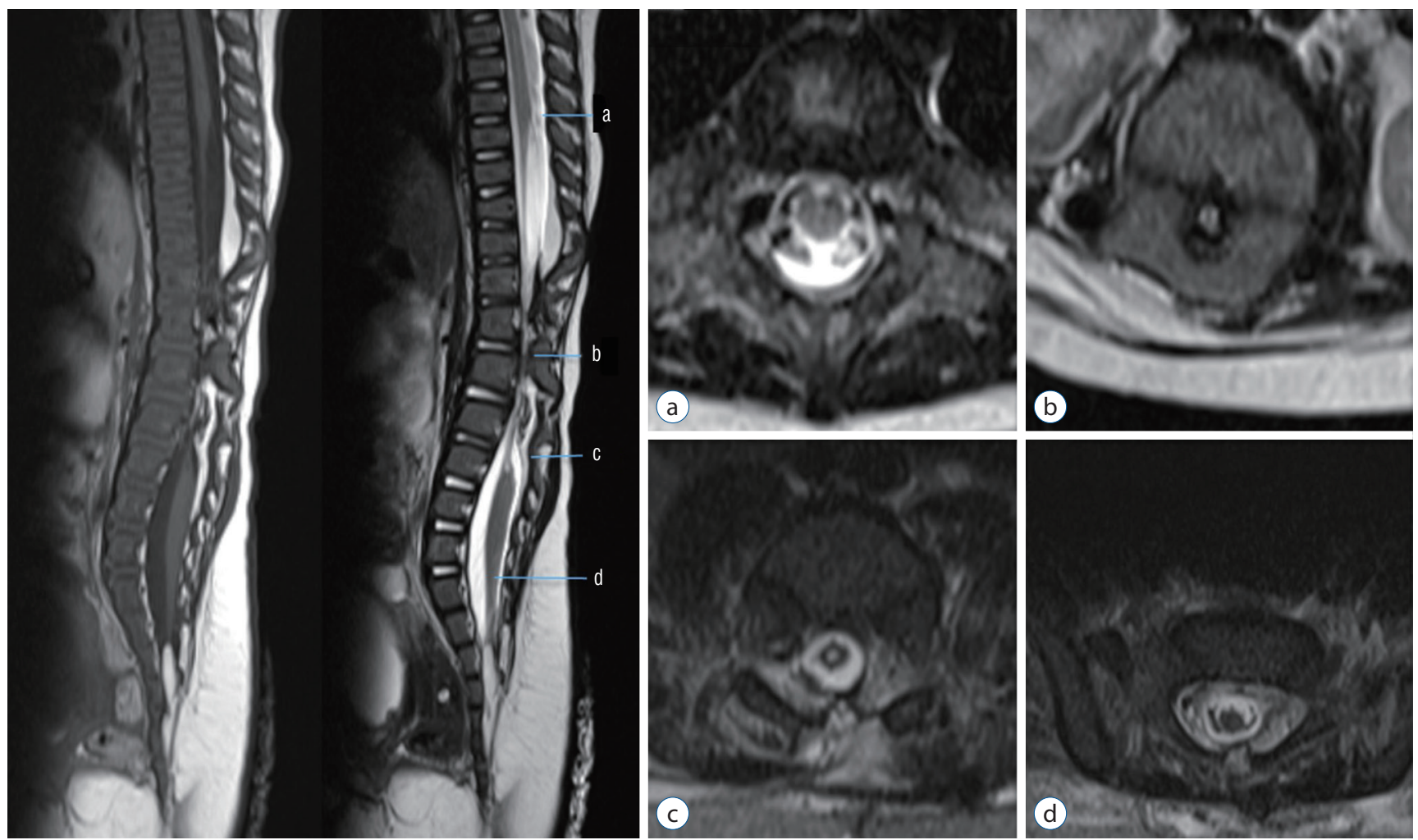

Fig. 1. Spinal MRI of Juntional neural tube defect patient. (a) Normal looking spinal cord in mid-thoracic level. The upper spinal cord tapered abruptly at T10. (b, c) The spinal cord narrowed and seemed to be a very thin band between T10 and L2. (d) The thin band expanded into the comparatively normal shape of the spinal cord and the conus from L2 and downward. Showed low-lying conus, at S2 and fatty filum. Reprinted from Wang et al. ${ }^{19)}$ with permission from Springer Nature.

spinal cord segments are connected by non-functional thin fibrous tissue. Images reveal the T10-11 to S1-2 level of the caudal end of the upper spinal cord and cranial end of the lower spinal cord. The average disconnection length between neural tubes is 4.5 vertebral segment levels. Most of the patients in the literature suffered lower extremity weakness and urinary incontinence due to the unconnected spinal cords and the loss of descending stimulation or inhibition from the upper segment of the central nervous system.

JNTD patients often exhibit foot deformity, incontinence, motor dysfunction of the lower extremity, or scoliosis. Five patients showed bilateral motor weakness below L5. Two patients with relatively higher disjunction levels had motor weakness below L2. Six patients showed hypesthesia or anesthesia below the level that correlates with motor weakness (one patient was not evaluated). No patients had voluntary contraction of an external anal sphincter. Except for two patients, all patients showed kidney ultrasonography or urodynamic study abnormalities. Spinal deformity was observed in all patients.
Surgical intervention was performed on five patients, but there was no improvement in neurological or urological symptoms, except in one patient with spasticity.

The functional disconnection between the upper (primary) and the lower (secondary) cord with the relatively 'intact' local circuit of the lower spinal cord is supported by the intraoperative neurophysiologic monitoring (IONM) findings. Transcortical stimulation elicited no responses in the abductor hallucis or sphincter muscles as expected. However, direct stimulation of the rootlets from the lower spinal cord produced electromyographic responses of the ankle and/or sphincter muscles. Furthermore, robust bulbocavernosus reflex was demonstrated bilaterally. In addition to the IONM results, the bladder hyperactivity and detrusor-sphincter dyssynergia of the patients may be explained by an intact local sensory-motor neuronal arc which became hyperactive due to the loss of suprasegmental inhibition, providing supportive evidence of the functional disconnection between the two spinal cords. 
Although JNTD was relatively recently classified as a new spinal dysraphism entity, the number of cases is likely underreported because segmental spinal dysgenesis (SSD) shares similar characteristics with JNTD ${ }^{18,19)}$. SSD is a rare disease entity that is well known to orthopedists, and it is described with more focus on bony anomalies. SSD is defined as localized agenesis or dysgenesis of the spine and focal abnormalities of the spinal cord and nerve roots ${ }^{12,16)}$. The T10 to L2 segments are often involved $\mathrm{d}^{2,3,6,10,11,17)}$.

\section{REVIEW OF THE EMBRYOLOGY OF JUNCTION- AL NEURULATION}

Based on the morphological properties of the JNTD (i.e., a relatively well-formed low-lying distal neural tube connected to the proximal neural tube via a thin string) and the results of neurophysiological monitoring during surgery, Eibach et al. ${ }^{7)}$ hypothesized that JNTD was a deformity caused by problems in the process of junctional neurulation between the primary and secondary neural tubes.

The central nervous system is formed via two modes of neurulation. Schoenwolf and Smith ${ }^{15)}$ described the primary and secondary neurulations of a chick embryo by shaping and bending. After posterior neuropore closure, secondary neurulation begins. Remnants of Hensen's node and a primitive streak form the caudal cell mass, which is the origin of the secondary neural tube. The medullary cord develops in the caudal cell mass via aggregation and condensation. The rodshaped medullary cord undergoes multiple cavitations, and these cavities coalesce together to create a larger lumen with continuity of the primary neural tube. However, the exact process of how the two neural tubes connect is not known, and the location of the junction of the primary and secondary neural tubes is not clear. Various studies on 'junctional neurulation' are found in the literature.

Criley described the presence of an overlap zone in the lumbosacral region in chick embryos for the first time ${ }^{4)}$. The primary neural tube occurred dorsally, and the secondary neural tube occurred ventrally. These tubes merged to form a single neural tube in a very short time ${ }^{4}$. However, the exact extent of the junctional area, which is composed of the two types of neural tubes, was not noted.

Schoenwolf and Delongo ${ }^{14)}$ observed the morphogenetic de- velopmental process of secondary neurulation at the ultrastructural level. They observed the overlap process during Hamburger-Hamilton (HH) stage 14-16 within the future lumbosacral region in chick embryos. Most of the cranial part of the junctional zone was occupied by the neural tube originating from the neural plate, and it was progressively replaced by neural tissue originating from the medullary cord as it went down to the caudal part. Le Douarin et al." revealed a primary and secondary neural tube interface at the level of the 27th somite, which corresponds with the hind limb bud level in chicken embryos.

Dady et al. ${ }^{5)}$ presented the junctional neurulation process using cell fate tracking methods, such as dil (1,1-dioctadecyl3,3,3',3'-tetramethyl indocarbocyanine perchlorate)-crystal mapping and fluorescent dye cell tracing experiments. They investigated the normal development process of junctional neural tube timing through HH8 to HH12 (time of posterior neuropore closure) of chick embryos. They also noted that neural tube defects in humans occur in the thoracolumbar region, most of which corresponds to the junction of the two cords. In situ hybridization was used to visualize the neurulation process using specific RNA expression and closely examined. Notably, the node streak border (NSB) was illustrated where junctional neurulation occurred at the thoracic level in chicks and the thoracolumbar level in humans. They revealed that limited cells in the midline of the rostral NSB underwent epithelium-to-mesenchyme transition at HH8 and formed a secondary neural tube. However, neural plate cells, which are in the area of origin of the primary neural tube, did not undergo epithelium-to-mesenchyme transition. Sox-2, E-cadherin, and N-cadherin expression allowed researchers to estimate the junction area between the continuous spinal cords. They found that the planar cell polarity pathway and the Prickle-1 mutation were responsible for the JNTDs. Prickle-1 was rarely found in the primary neural tube. In contrast, it was prominently noticeable in the NSB and helped identify the location of the junctional neural tube. Prickle-1 mutation caused an anomaly in the chick embryo with the characteristics of caudal defects, open rostral neural tube defects, and poorly connected caudal structures (secondary neural tubes) at a specific time and in a limited space.

The pathoembryogenesis of JNTD and the frequently associated SSD is not certain. Further studies are needed to gain insight into the structure of junctional neurulation and the 
molecular characteristics of the constituent cells.

\section{CONCLUSION}

The clinical features of a new entity, JNTD were summarized, and the related embryological background was reviewed. Many unanswered questions on the process of junctional neurulation remain, and the pathoembryogenesis of JNTD is not certain. Further studies on the structure of junctional neurulation and the molecular characteristics of the constituent cells are needed.

\section{CONFLICTS OF INTEREST}

No potential conflict of interest relevant to this article was reported.

\section{INFORMED CONSENT}

This type of study does not require informed consent.

\section{AUTHOR CONTRIBUTIONS}

\author{
Conceptualization : JYL \\ Data curation : KHK \\ Formal analysis : KHK \\ Funding acquisition : JYL \\ Methodology : KHK \\ Project administration : JYL \\ Visualization : KHK \\ Writing - original draft : KHK \\ Writing - review \& editing : KHK, JYL
}

\section{ORCID}

Kyung Hyun Kim https://orcid.org/0000-0002-8238-2043

Ji Yeoun Lee https://orcid.org/0000-0003-0464-7605

\section{- Acknowledgements}

This work was supported by the National Research Foundation of Korea (NRF) Grant funded by the Korean Govrnment (MSIT) (NRF-2018R1A5A2025964)

\section{References}

1. Ali M, McNeely PD : Junctional neural tube defect: a supporting case report. Childs Nerv Syst 34 : 1447-1448, 2018

2. Bristol RE, Theodore N, Rekate HL : Segmental spinal dysgenesis: report of four cases and proposed management strategy. Childs Nerv Syst 23 : 359-364, 2007

3. Cacciola F, Lippa $\mathrm{L}$ : Segmental spinal dysgenesis associated with occult dysraphism: considerations on management strategies. J Craniovertebr Junction Spine 8 : 144-148, 2017

4. Criley BB : Analysis of embryonic sources and mechanims of development of posterior levels of chick neural tubes. J Morphol 128 : 465501, 1969

5. Dady A, Havis E, Escriou V, Catala M, Duband JL : Junctional neurulation: a unique developmental program shaping a discrete region of the spinal cord highly susceptible to neural tube defects. J Neurosci 34 : 13208-13221, 2014

6. Desai K, Nadkarni T, Bhayani R, Goel A : Congenital thoracic cord segmental amyelia: a rare manifestation of segmental spinal dysgenesis. Pediatr Neurosurg 38 : 102-106, 2003

7. Eibach S, Moes G, Hou YJ, Zovickian J, Pang D : Unjoined primary and secondary neural tubes: junctional neural tube defect, a new form of spinal dysraphism caused by disturbance of junctional neurulation. Childs Nerv Syst 33 : 1633-1647, 2017

8. Florea SM, Faure A, Brunel H, Girard N, Scavarda D : A case of junctional neural tube defect associated with a lipoma of the filum terminale: a new subtype of junctional neural tube defect? J Neurosurg Pediatr $21: 601-605,2018$

9. Le Douarin NM, Teillet MA, Catala M : Neurulation in amniote vertebrates: a novel view deduced from the use of quail-chick chimeras. Int J Dev Biol 42 : 909-916, 1998

10. Morell SM, McCarthy RE, Ocal E : Segmental spinal dysgenesis: a report of early surgical intervention and outcome in a 14-month-old child. Childs Nerv Syst 33 : 381-384, 2017

11. Ofiram E, Winter RB, Lonstein JE : Segmental spinal dysgenesis: case report of a 50-year follow-up after surgery at age 3 years: case report. Spine (Phila Pa 1976) 31 : E59-E61, 2006

12. Pavlova OM, Ryabykh SO, Kozyrev DA, Gubin AV : Surgical treatment of thoracolumbar segmental spinal dysgenesis: optimal type of fusion. World Neurosurg 106 : 551-556, 2017

13. Schmidt C, Voin V, Iwanaga J, Alonso F, Oskouian RJ, Topale N, et al. : Junctional neural tube defect in a newborn: report of a fourth case. Childs Nerv Syst $33: 873-875,2017$ 
14. Schoenwolf GC, Delongo J : Ultrastructure of secondary neurulation in the chick embryo. Am J Anat $158:$ 43-63, 1980

15. Schoenwolf GC, Smith JL : Mechanisms of neurulation: traditional viewpoint and recent advances. Development 109 : 243-270, 1990

16. Scott RM, Wolpert SM, Bartoshesky LE, Zimbler S, Karlin L : Segmental spinal dysgenesis. Neurosurgery $22: 739-744,1988$

17. Tortori-Donati P, Fondelli MP, Rossi A, Raybaud CA, Cama A, Capra $\checkmark$ : Segmental spinal dysgenesis: neuroradiologic findings with clinical and embryologic correlation. AJNR Am J Neuroradiol 20 : 445-456, 1999

18. Wang KC, Lee JY : Reply to the comments by Eibach et al. Childs Nerv Syst 36 : 1097, 2020

19. Wang KC, Lee JS, Kim K, Im YJ, Park K, Kim KH, et al. : Do junctional neural tube defect and segmental spinal dysgenesis have the same pathoembryological background? Childs Nerv Syst 36 : 241-250, 2020 